www.nature.com/ja

\title{
Jogyamycin, a new antiprotozoal aminocyclopentitol antibiotic, produced by Streptomyces sp. a-WM-JG- 16.2
}

\author{
Masato Iwatsuki ${ }^{1}$, Aki Nishihara-Tsukashima ${ }^{1}$, Aki Ishiyama ${ }^{1}$, Miyuki Namatame ${ }^{1}$, Yoshio Watanabe ${ }^{2}$, \\ Siti Handasah ${ }^{3}$, Hardaning Pranamuda ${ }^{3}$, Bambang Marwoto ${ }^{3}$, Atsuko Matsumoto ${ }^{4}$, Yoko Takahashi ${ }^{4}$, \\ Kazuhiko Otoguro ${ }^{1}$ and Satoshi Ōmura ${ }^{4}$
}

The Journal of Antibiotics (2012) 65, 169-171; doi:10.1038/ja.2011.136; published online 11 January 2012

Keywords: antimalarial; antitrypanosomal; jogyamycin; Streptomyces sp.

During our search for new antiprotozoal (antimalarial and antitrypanosomal) agents, we have tested culture extracts of soil microorganisms from a variety of sources, including those isolated by the Kitasato Institute for Life Sciences and the Bioresource Laboratories, MicroBiopharm Japan Corporation. We have previously discovered a variety of microbial metabolites exhibiting antiprotozoal, ${ }^{1,2}$ antimalarial ${ }^{3,4}$ and antitrypanosomal properties. ${ }^{5,6}$ Recently, we have isolated a new derivative of pactamycin, designated as jogyamycin (Figure 1), from a culture broth of Streptomyces sp. a-WM-JG-16.2. This compound has proved to have potent antiprotozoal activity (Table 2). Here, we report the fermentation, isolation, structure elucidation and biological activity of this novel aminocyclopentitol antibiotic.

The producing organism, strain a-WM-JG-16.2 was isolated from a soil sample collected in Jogjakarta, Indonesia, using the sucrose density gradient centrifugation method. ${ }^{7}$ Using the basic local alignment search tool (BLAST), we compared the 16S rRNA gene sequences available in the EzTaxon server to identify the species of strain a-WM-JG-16.2. Streptomyces sp. a-WM-JG-16.2 was classified as a species of the genus Streptomyces; the 16S rRNA gene sequence comparison showing a $100 \%$ similarity with S. griseoruber NBRC12873 (AB184209).

The strain was cultured on a rotary shaker $\left(220\right.$ r.p.m.) at $28^{\circ} \mathrm{C}$ for 5 days in $500-\mathrm{ml}$ Erlenmeyer flasks (20 flasks) containing $50 \mathrm{ml}$ of a production medium containing $2 \%$ rice starch (Rose brand, Cikampek, Indonesia), 2\% glucose (Univar, Sydney, NSW, Australia), $2 \%$ soybean meal (J-Oil Mills, Tokyo, Japan), $0.5 \%$ yeast extract
(Himedia, Mumbai, India), $0.25 \% \mathrm{NaCl}$ (Univar), $0.32 \% \mathrm{CaCO}_{3}$ (Univar), 5 p.p.m. $\mathrm{CuSO}_{4} \cdot 5 \mathrm{H}_{2} \mathrm{O}$ (Merck, Darmstadt, Germany), 5 p.p.m. $\mathrm{MnCl}_{2} \cdot 4 \mathrm{H}_{2} \mathrm{O}$ (Merck) and 5 p.p.m. $\mathrm{ZnSO}_{4} \cdot 7 \mathrm{H}_{2} \mathrm{O}$ (Merck), pH 7.4 (before sterilization).

The culture broth $(50 \mathrm{ml} \times 20$ flasks $)$ was extracted with $n$-butanol (1.51). The organic layer was evaporated to dryness in vacuo. This $n$-butanol extract $(0.87 \mathrm{~g})$ was applied to an ODS column (Pegasil Prep ODS-7515-12A, 2012A, 20 (Senshu Scientific Co., Tokyo, Japan)) pre-equilibrated with $12.5 \%$ methanol aq. The column was eluted stepwise with 20, 40 and $60 \%$ aqueous acetonitrile $(180 \mathrm{ml}$ each) and the active principals were found in the $60 \%$ acetonitrile eluate, which was concentrated in vacuo to yield a brown material $(58.2 \mathrm{mg})$. The material was washed with $50 \%$ aqueous acetonitrile $(5.8 \mathrm{ml})$, and the $50 \%$ acetonitrile-soluble portion was purified by HPLC using a L-column2 ODS $(20 \phi \times 250 \mathrm{~mm}$, CERI, Tokyo, Japan) with $20 \%$ acetonitrile/ $0.1 \%$ trifluoroacetic acid (TFA) at a flow rate of $7 \mathrm{ml} \mathrm{min}{ }^{-1}$ with UV detection at UV $210 \mathrm{~nm}$. The retention time of the active fraction was $9 \mathrm{~min}$. The active fraction was concentrated in vacuo to dryness to afford $2.5 \mathrm{mg}$ of jogyamycin (1). In the process of purification of 1, we also identified other known compounds, such as pactamycin (3), ${ }^{8} 7$-deoxypactamycin $(2)^{9}$ and pactamycate. ${ }^{10}$

Compound 1 was obtained as a light yellow powder $\left([\alpha]_{\mathrm{D}}^{23}-20.4\right.$ (c 0.1 in $\mathrm{MeOH}$ ); UV (MeOH) $\lambda_{\max }(\varepsilon), 239$ (5790), 263 (2200) and $350 \mathrm{~nm}(612))$. The IR spectrum showed characteristic absorptions at 3410 and $1679 \mathrm{~cm}^{-1}$, which suggested the presence of hydroxyl and carbonyl groups. The molecular formula of 1 was established by high

${ }^{1}$ Research Center for Tropical Diseases, Kitasato Institute for Life Sciences, Kitasato University, Tokyo, Japan; ${ }^{2}$ Bioresource Laboratories, MicroBiopharm Japan Co., Ltd., Shizuoka, Japan; ${ }^{3}$ Biotech Center, BPPT, Selatan, Indonesia and ${ }^{4}$ Kitasato Institute for Life Sciences, Graduate School of Infection Control Sciences, Kitasato University, Tokyo, Japan

Correspondence: Dr K Otoguro or Professor S Ōmura, Research Center for Tropical Diseases, Kitasato Institute for Life Sciences, Graduate School of Infection Control Sciences, Kitasato University, 5-9-1 Shirokane, Minato-ku, Tokyo 108-8641, Japan.

E-mail: otoguro@lisci.kitasato-u.ac.jp or omuras@insti.kitasato-u.ac.jp

Received 19 October 2011; revised 12 December 2011; accepted 16 December 2011; published online 11 January 2012 
resolution-FAB-MS to be $\mathrm{C}_{20} \mathrm{H}_{32} \mathrm{O}_{5} \mathrm{~N}_{4}\left(\mathrm{~m} / z 409.2437[\mathrm{M}+\mathrm{H}]^{+}\right.$calcd. 409.2451), requiring seven double bond equivalents. The ${ }^{1} \mathrm{H}$ and ${ }^{13} \mathrm{C}$ NMR spectral data of $\mathbf{1}$, listed in Table 1 , were similar to those of 7-deoxypactamycin. ${ }^{9}$ The ${ }^{1} \mathrm{H}$ NMR, ${ }^{13} \mathrm{C}$ NMR, HSQC and HMBC spectra indicated 20 carbons that were classified into one ketone carbonyl carbon $\left(\delta_{\mathrm{C}} 201.5\right)$, one urea carbonyl carbon $\left(\delta_{\mathrm{C}} 160.9\right)$, four $s p^{2}$ methine aromatic carbons, two $s p^{2}$ quartenary aromatic carbons, two $s p^{3}$ methine carbons, three $s p^{3}$ quaternary carbons, two $s p^{3}$ methylene carbons and five methyl carbons, thus accounting for six double bond equivalents. Therefore, the remaining double bond equivalent was likely to be because of a ring structure. As shown by the bold lines for 1 in Figure 2, two partial structures from $\mathrm{H}-2\left(\delta_{\mathrm{H}}\right.$ 3.65) to $\mathrm{H}-3\left(\delta_{\mathrm{H}} 4.11\right)$ and from $\mathrm{H}_{2}-7\left(\delta_{\mathrm{H}} 2.13,2.45\right)$ to $\mathrm{H}_{3}-8\left(\delta_{\mathrm{H}}\right.$ $0.98)$ were revealed by COSY. The coupling pattern of the aromatic protons and the $\mathrm{HMBC}$ correlations from $\mathrm{H}-2^{\prime}\left(\delta_{\mathrm{H}} 7.37\right)$ to $\mathrm{C}-6^{\prime}\left(\delta_{\mathrm{C}}\right.$ $118.8)$ and $\mathrm{C}-4^{\prime}\left(\delta_{\mathrm{C}} 119.3\right)$, from $\mathrm{H}-4^{\prime}\left(\delta_{\mathrm{H}} 7.02\right)$ to $\mathrm{C}-2^{\prime}\left(\delta_{\mathrm{C}} 113.1\right)$, from $\mathrm{H}-5^{\prime}\left(\delta_{\mathrm{H}} 7.26\right)$ to $\mathrm{C}-1^{\prime}\left(\delta_{\mathrm{C}} 139.2\right)$ and $\mathrm{C}-3^{\prime}\left(\delta_{\mathrm{C}} 149.9\right)$, from $\mathrm{H}-6^{\prime}$ $\left(\delta_{\mathrm{H}} 7.29\right)$ to $\mathrm{C}-2^{\prime}$, and from $\mathrm{H}_{3}-8^{\prime}\left(\delta_{\mathrm{H}} 2.56\right)$ and $\mathrm{H}-2^{\prime}$ to $\mathrm{C}-7^{\prime}\left(\delta_{\mathrm{C}}\right.$ 201.5) revealed the presence of a $m$-aminoacetophenone unit. On the basis of ${ }^{1} \mathrm{H}_{-}{ }^{13} \mathrm{C}$ HMBC experiments, the correlations from $\mathrm{H}-3$ to $\mathrm{C}-4$ $\left(\delta_{\mathrm{C}} 83.4\right)$ and $\mathrm{C}-5\left(\delta_{\mathrm{C}} 83.3\right)$; from $\mathrm{H}_{2}-9\left(\delta_{\mathrm{H}} 3.48,4.06\right)$ to C-4 and C5; from $\mathrm{H}_{3}-6\left(\delta_{\mathrm{H}} 1.55\right)$ to $\mathrm{C}-1\left(\delta_{\mathrm{C}} 69.0\right), \mathrm{C}-4$ and C-5; from $\mathrm{H}_{2}-7\left(\delta_{\mathrm{H}}\right.$

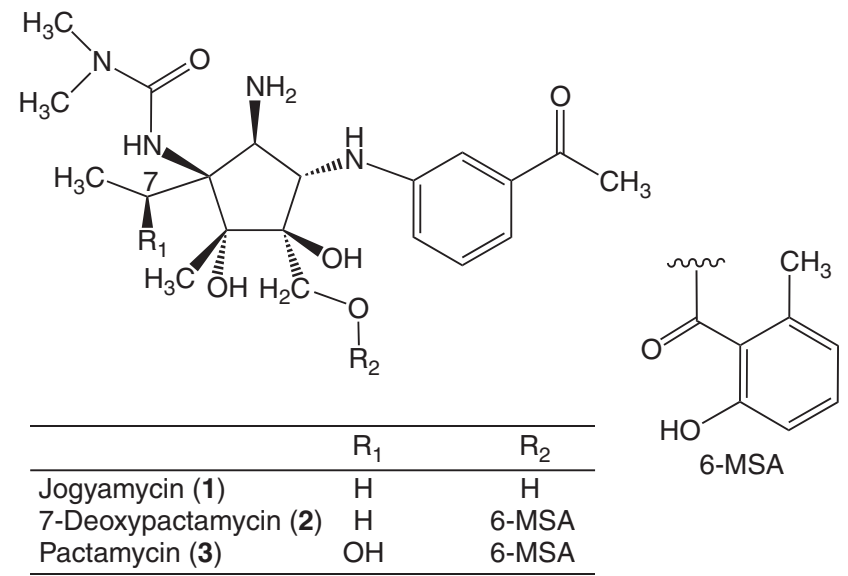

Figure 1 Structures of jogyamycin (1) and related compounds. 6-MSA, 6-methyl salicylic acid.
$2.13,2.45)$ to $\mathrm{C}-1$ and $\mathrm{C}-5$; from $\mathrm{H}_{3}-8\left(\delta_{\mathrm{H}} 0.98\right)$ to $\mathrm{C}-1$; and from $\mathrm{H}_{3}$ 11 and $\mathrm{H}_{3}-12\left(\delta_{\mathrm{H}} 3.00\right)$ to $\mathrm{C}-10\left(\delta_{\mathrm{C}} 160.9\right), \mathrm{C}-11$ and $\mathrm{C}-12\left(\delta_{\mathrm{C}} 36.8\right)$, indicated the presence of the aminocyclopentitol core attached to an ${ }^{1} \mathrm{~N},{ }^{1} \mathrm{~N}$-dimethylurea moiety. Finally, by HMBC correlation from $\mathrm{H}-3$ to C-3', the structure of $\mathbf{1}$ was elucidated as an analog of 7 deoxypactamycin lacking the 6-methyl salicylic acid (6-MSA) moiety, and it was subsequently designated as jogyamycin (1).

In vitro antiprotozoal activities were investigated using the Plasmodium falciparum $\mathrm{K} 1$ strain (drug resistant), as well as a Trypanosoma brucei brucei strain GUTat 3 model. ${ }^{3,5}$ As shown in Table 2, jogyamycin (1) showed potent antimalarial and antitrypanosomal activities, with $\mathrm{IC}_{50}$ values of 1.5 and $12.3 \mathrm{~nm}$, respectively. The effect was $13.5-$ fold stronger than the antimalarial artemisinin, but 2.6-fold less active than the commonly used antitrypanosomal pentamidine. Compared with our previously reported antiprotozoal activities of pactamycin (3) and 7-deoxypactamycin (2), ${ }^{2}$ the antimalarial activity of 1 was 9.4fold more potent than that of $\mathbf{3}$, whereas its antitrypanosomal activity was similar. However, 1 was 3.8- and 14.7-fold less potent than 2 with regard to antimalarial and antitrypanosomal activity, respectively.

Cytotoxicity against the human diploid embryonic cell line MRC-5 was measured as described previously. ${ }^{3}$ Among pactamycin and its two analogs, 1 showed the highest cytotoxicity displaying an $\mathrm{IC}_{50}$ value of $5.6 \mathrm{~nm}$. Its cytotoxicity was $5-17$-fold more potent than those of 2 and 3. Jogyamycin showed the lowest selectivity indexes (Selectivity index: cytotoxicity ( $\mathrm{IC}_{50}$ for the MRC-5 cells)/antitrypanosomal or antimalarial activity ( $\mathrm{IC}_{50}$ for the GUTat 3.1 strain or the $\mathrm{K} 1$ strain)), with ratios of around $0.5-4$. These results provide a very interesting insight with regard to structure-activity relationships. The

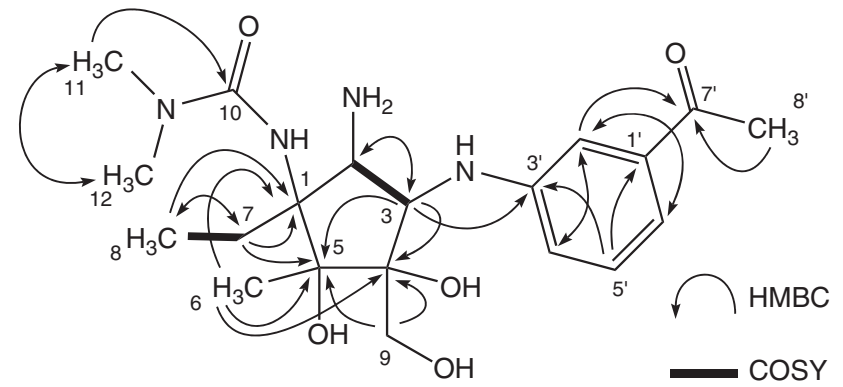

Figure 2 COSY and HMBC correlations of jogyamycin (1).

Table $1{ }^{1} \mathrm{H}$ and ${ }^{13} \mathrm{C}$ NMR spectral data of jogyamycin (1) in $\mathrm{CD}_{3} \mathrm{OD}$

\begin{tabular}{|c|c|c|c|c|c|}
\hline \multirow[b]{2}{*}{ Position } & \multicolumn{5}{|c|}{ Jogyamycin (1) } \\
\hline & $\delta_{C}$ & $\delta_{H}$ (int., mult., $J$ in $H z$ ) & Position & $\delta_{C}$ & $\delta_{H}$ (int., mult., $\mathrm{J}$ in $\mathrm{Hz}$ ) \\
\hline 1 & 69.0 & - & 10 & 160.9 & - \\
\hline 2 & 64.8 & $3.65(1 \mathrm{H}, \mathrm{d}, 9.5)$ & 11 & 36.8 & $3.00(3 \mathrm{H}, \mathrm{s})$ \\
\hline 3 & 66.1 & $4.11(1 \mathrm{H}, \mathrm{d}, 9.5)$ & 12 & 36.8 & $3.00(3 \mathrm{H}, \mathrm{s})$ \\
\hline 4 & 83.4 & - & $1^{\prime}$ & 139.2 & - \\
\hline 5 & 83.3 & - & $2^{\prime}$ & 113.1 & $7.37(1 \mathrm{H}, \mathrm{br} . \mathrm{s})$ \\
\hline 6 & 19.2 & $1.55(3 \mathrm{H}, \mathrm{s})$ & $3^{\prime}$ & 149.9 & - \\
\hline \multirow[t]{2}{*}{7} & 21.5 & $2.13(1 \mathrm{H}, \mathrm{dq}, 14.9,7.5)$ & $4^{\prime}$ & 119.3 & $7.02(1 \mathrm{H}, \mathrm{d}, 8.1)$ \\
\hline & & $2.45(1 \mathrm{H}, \mathrm{dq}, 14.9,7.5)$ & $5^{\prime}$ & 130.3 & $7.26(1 \mathrm{H}, \mathrm{dd}, 8.1,7.5)$ \\
\hline 8 & 9.4 & $0.98(3 \mathrm{H}, \mathrm{t}, 7.5)$ & $6^{\prime}$ & 118.8 & $7.29(1 \mathrm{H}, \mathrm{d}, 7.5)$ \\
\hline \multirow[t]{2}{*}{9} & 63.3 & $3.48(1 \mathrm{H}, \mathrm{d}, 11.5)$ & $7^{\prime}$ & 201.5 & - \\
\hline & & $4.06(1 \mathrm{H}, \mathrm{d}, 11.5)$ & $8^{\prime}$ & 26.8 & $2.56(3 \mathrm{H}, \mathrm{s})$ \\
\hline
\end{tabular}

Measured in $\mathrm{CD}_{3} \mathrm{OD}\left({ }^{1} \mathrm{H}: 500 \mathrm{MHz},{ }^{13} \mathrm{C}: 125 \mathrm{MHz}\right)$. 
Table 2 In vitro antimalarial and antitrypanosomal activity, and cytotoxicity in human MRC-5 cells of jogyamycin (1) and related compounds

\begin{tabular}{|c|c|c|c|c|c|}
\hline \multirow[b]{3}{*}{ Compound } & \multicolumn{3}{|c|}{$1 C_{50}(n M)$} & & \\
\hline & \multicolumn{2}{|c|}{ Antiprotozoal activity } & \multirow{2}{*}{$\begin{array}{c}\text { Cytotoxicity } \\
\text { (MRC-5) }\end{array}$} & \multicolumn{2}{|c|}{ Selectivity index (SI) } \\
\hline & P.f. $K 1^{\mathrm{a}}$ & T. b. b. GUTat $3.1^{\mathrm{b}}$ & & $M C R-5 / K 1$ & MCR-5/GUTat \\
\hline Jogyamycin (1) & 1.5 & 12.3 & 5.6 & 4 & 0.5 \\
\hline 7-Deoxypactamycin $(2)^{c}$ & 0.4 & 0.9 & 29.5 & 74 & 33 \\
\hline Pactamycin $(3)^{c}$ & 14.2 & 7.4 & 95 & 7 & 13 \\
\hline \multicolumn{6}{|c|}{ 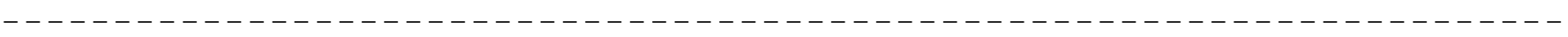 } \\
\hline Artemisinin $^{d}$ & 20.2 & 3333 & 160177 & 7930 & 48 \\
\hline Chloroquined & 575 & ND & 57900 & 101 & - \\
\hline Pentamidine $^{\mathrm{e}}$ & ND & 4.7 & 16794 & - & 3566 \\
\hline Suramin ${ }^{\mathrm{e}}$ & ND & 1106 & $>69979$ & - & $>63$ \\
\hline
\end{tabular}

Abbreviation: ND, not determined.

a Plasmodium falciparum $\mathrm{K} 1$ (drug resistant)

'Trypanosoma brucei brucei GUTat 3.1.

${ }^{\mathrm{C}}$ The $\mathrm{IC}_{50}$ values were reported in ref. 2.

dAntimalarial drugs used clinically.

eAntitrypanosomal drugs used clinically.

lack of the 6-MSA moiety of 7-deoxypactamycin causes jogyamycin to show 3.8-14.7-fold less antiprotozoal activity and 5-fold more potent cytotoxicity than 7-deoxypactamycin.

Pactamycin and 7-deoxypactamycin, which was originally isolated as cranomycin, are aminocyclopentitol antibiotics, posessing antibacterial and antitumor activity. ${ }^{8,9}$ It is known that pactamycin acts by inhibition of the initiation of protein synthesis. ${ }^{11}$ Recently, Ito et al. ${ }^{12}$ isolated de-6-MSA-pactamycin and de-6-MSA-pactamycate from the knockout ptmQ (6-MSA synthase gene) mutant of the pactamycin- and pactamycate-producing strain, Streptomyces pactum; ATCC 27456 . This mutant was not able to produce pactamycin and pactamycate, which accumulated the intermediates of pactamycin biosynthesis. Although de-6-MSA-7-deoxypactamycin (jogyamycin, 1) was also thought to be a biosynthetic intermediate of pactamycin, it was not isolated from this mutant but from a wild-type organism, Streptomyces sp. a-WM-JG-16.2. Ito et al. ${ }^{12}$ reported that de-6-MSA-pactamycin showed antibacterial and antitumor activities similar to pactamycin, and they suggested that the 6MSA moiety of pactamycin is not essential for antibacterial and antitumor activities. However, our data indicate that the 6-MSA moiety in 7-deoxypactamycin increases antiprotozoal activity, as well as decreasing cytotoxicity in human cells, suggesting that the 6-MSA moiety has an important role in both antiprotozoal activity and cytotoxicity.

The above results reveal that the analogs of pactamycin are promising lead compounds for the development of new antiprotozoal drugs. Recently, the first total synthesis of pactamycin was achieved, allowing the prospect of synthesis of less cytotoxic analogs that maintain their antibacterial and antiprotozoal properties. ${ }^{13}$ Therefore, further investigation of the selective antiprotozoal analogs and their in vivo evaluation is in progress. Furthermore, the producing strain of 1, Streptomyces sp. a-WM-JG-16.2, will be useful in analysis of the biosynthesis of pactamycin.

\section{ACKNOWLEDGEMENTS}

This study was supported, in part, by the funds from the Drugs for Neglected Diseases initiative (DNDi), Quality Assurance Framework of Higher Education from the Ministry of Education, Culture, Sports, Science and Technology (MEXT) in Japan, and All Kitasato Project Study (AKPS). We are grateful to Ms Hitomi Sekiguchi and Mr Toshiaki Furusawa for their technical assistance, Dr Kenichiro Nagai and Ms Noriko Sato, School of Pharmacy, Kitasato University for the measurements of mass and NMR spectra, and Dr Kazuro Shiomi, Kitasato Institute for Life Sciences, Kitasato University for proofreading this paper.

1 Otoguro, K. et al. In vitro and in vivo antiprotozoal activities of bispolides and their derivatives. J. Antibiot. 63, 275-277 (2010).

2 Otoguro, K. et al. Promising lead compounds for novel antiprotozoals. J. Antibiot. 63, 381-384 (2010).

3 Otoguro, K. et al. Potent antimalarial activities of the polyether antibiotic, X-206. J. Antibiot. 54, 658-663 (2001).

4 Iwatsuki, M. et al. In vitro and in vivo antimalarial activity of puberulic acid and its new analogs, viticolins A-C, produced by Penicillium sp. FKI-4410. J. Antibiot. 64, 183-188 (2011).

5 Otoguro, K. et al. Selective and potent in vitro antitrypanosomal activities of 10 microbial metabolites. J. Antibiot. 61, 372-378 (2008).

6 Ishiyama, A. et al. In vitro and in vivo antitrypanosomal activities of two microbial metabolites, KS-505a and Alazopeptin. J. Antibiot. 61, 627-632 (2008).

7 Yamamura, $\mathrm{H}$. et al. Application of sucrose-gradient centrifugation for selective isolation of Nocardia spp. from soil. J. Appl. Microbiol. 95, 677-685 (2003).

8 Argoudelis, A. D., Jahnke, H. K. \& Fox, J. A. Pactamycin, a new antitumor antibiotic. II. Isolation and characterization. Antimicrob. Agents Chemother. 1-1961, 191-197 (1962).

9 Kondo, S., Shimura, M., Sezaki, M., Satō, K. \& Hara, T. Isolation and characterization of cranomycin, a new antibiotic. J Antibiot. Ser. A 17, 230-233 (1964).

10 Weller, D. D., Haber, A., Rinehart, K. L. Jr. \& Wiley, P. F. Carbon-13 nuclear magnetic resonance assignments to pactamycin and related compounds. J. Antibiot. 31, 997-1006 (1978)

11 Brodersen, D. E. et al. The structural basis for the action of the antibiotics tetracycline, pactamycin, and hygromycin B on the 30s ribosomal subunit. Cell 103, 1143-1154 (2000).

12 Ito, T. et al. Deciphering pactamycin biosynthesis and engineered production of new pactamycin analogues. Chem. BioChem. 10, 2253-2265 (2009).

13 Hanessian, S. et al. Total synthesis of pactamycin. Angew Chem. Int. Ed. Engl. 50, 3497-3500 (2011). 